\title{
COMPARATIVE STUDY BETWEEN DEXMEDETOMIDINE AND FENTANYL AS AN ADJUVANT TO BUPIVACAINE IN ULTRASOUND-GUIDED INTERSCALENE BRACHIAL PLEXUS BLOCK IN ARTHROSCOPIC SHOULDER SURGERIES
}

\author{
Mostafa K. Fouad; Waleed A. Al Taher; Ayman A. Abdellatif and Sara H. Saleh
}

\footnotetext{
${ }^{1}$ Department of Anesthesia, Intensive Care and Pain Management, Faculty of Medicine, Ain Shams University, Cairo, Egypt. Corresponding :

Sarah Saleh Mobile: 01001584305

E mail:

Sara_7ossam@hotmail.com Received: 16/10/2019

Accepted: $12 / 11 / 201$
}

\begin{abstract}
Background: Poorly controlled acute pain after shoulder surgery is associated with a variety of unwanted post-operative consequences, including patient suffering, prolonged hospital stays and an increased likelihood of chronic pain. The interscalene block is the gold standard for shoulder anesthesia and the most commonly used block for shoulder procedures.
\end{abstract}

Aim of the work: to compare the effects of adding either 100 micro-grams of dexmedetomidine or 50 micro-grams of fentanyl to bupivacaine in ultrasound-guided interscalene nerve block, as regards the onset and the duration of the sensory and motor block, and the duration of post-operative analgesia.

Patients \&Methods:75 patients of either sex, ASA physical status (I, II) scheduled for elective arthroscopic surgeries of shoulder under ultrasound guided interscalene brachial plexus block at Ain Shams University Hospitals who were randomly divided into 3 equal groups; Group C: 25 patients received a total volume of $30 \mathrm{ml}$ bupivacaine $0.5 \%$. Group D: 25 patients received a total volume of $30 \mathrm{ml}$ bupivacaine $0.5 \%$ added to 100 micrograms of dexmedetomidine, Group F: 25 patients received a total volume of $30 \mathrm{ml}$ bupivacaine $0.5 \%$ added to 50 micrograms of fentanyl.

Results: This study showed that addition of a 100 micro gram of dexmedetomidine to bupivacaine in interscalene nerve block shortens the onset times of sensory and motor block and prolongs their duration in comparison to 50 micro-gram of fentanyl when added to bupivacaine, and to bupivacaine when used alone, also dexmedetomidine got and added effect of conscious sedation with minimal side effect.

Conclusions: Our study showed that addition of dexmedetomidine to bupivacaine in interscalene nerve block shortened the onset times of both sensory and motor blocks and prolonged their durations. This occurred in comparison to fentanyl when added to bupivacaine and to bupivacaine when used alone.

Keywords: Dexmedetomidine; Fentanyl; Bupivacaine; Interscalene Brachial Plexus Block

\section{INTRODUCTION}

Postoperative pain after orthopedic surgery can be intense. In particular, pain management after shoulder procedures poses a challenge to both anesthesiologists and orthopedic surgeons ${ }^{(1)}$. 
Patients report severe pain on the first postoperative day after the wear off of local anesthetics' effect. Therefore, prolonging the duration of local anesthetics is desirable for decreasing postoperative pain and improving patients' satisfaction. A number of local anesthetic adjuvants, such as alpha-2 adrenergic agonists, ketamine, and corticosteroids, have been evaluated for their abilities to prolong the analgesic duration of brachial plexus blocks, and results have varied $^{(2)}$.

Dexmedetomidine is a potent and highly selective $\alpha-2$ adrenoceptor agonist with sympatholytic, sedative, amnestic, and analgesic properties, which has been described as a useful and safe adjunct in many clinical applications $^{(3)}$.

There have been clinical studies evaluating the effect of mixing Dexmedetomidine with local anesthetics during peripheral nerve blockade. Peripheral analgesic effects of Dexmedetomidine have enabled an overall improved blockade quality when added to local anesthetics in a peripheral nerve block model which is thought to be mediated by $\alpha 2$ receptor binding. Dexmedetomidine also causes local vasoconstriction resulting in delay of absorption of local anesthetics, thus prolonging its action ${ }^{(4)}$.

Fentanyl is a potent synthetic opioid that produces sedation and analgesia when administered intravenously; also, many authors believe that it also prolongs the effect of local anesthetics in peripheral nerve blocks $^{(5)}$.

\section{AIM OF THE WORK}

The aim of this work is to compare the effects of adding either Dexmedetomidine or Fentanyl to Bupivacaine in Ultrasound-guided Interscalene Brachial plexus nerve block as regard the block characteristics (onset of the block, quality of the block and the duration of post-operative analgesia).

\section{PATIENTS AND METHODS}

After obtaining approval from AinShams hospital academic and ethical committee, written, informed and valid consent will be taken from all participants after proper explanation of the study procedure and the expected outcome in a clear language.

Patients of either sex, aging from 25 to 55 years old, ASA physical status (I, II) scheduled for elective arthroscopic surgeries of shoulder under ultrasound guided interscalene brachial plexus block at Ain Shams University Hospitals, will be enrolled in this study.

Patients with the following criteria were excluded from the study: Patient refusal, ASA physical status III or more, known allergy to any of the study drugs, infection at the site of injection, history of cardiovascular, renal, hepatic or neuromuscular diseases, history of any psychiatric disorder, presence of any coagulopathy, chronic intake of analgesic drugs for any reason, polytraumatized patients, body weight less than $60 \mathrm{~kg}$, and pregnancy.

The study was done as a randomized prospective controlled study. Patients were divided randomly into 3 groups as follows: Group C (Control group): 25 patients received a total volume of $30 \mathrm{ml}$ of a mixture of Bupivacaine $0.5 \%$ and $1 \mathrm{ml}$ of normal saline. Group D (Dexmedetomidine group): 25 patients received a total volume of $30 \mathrm{ml}$ of a mixture of Bupivacaine $0.5 \%$ and 100 micrograms of Dexmedetomidine. Group F (Fentanyl group): 25 patients received a total volume of $30 \mathrm{ml}$ of a mixture of Bupivacaine $0.5 \%$ and 50 micrograms of Fentanyl.

\section{Preoperative evaluation and prepara- tions:}

Full detailed history, clinical examination and routine investigations including; electrocardiogram (ECG), 
complete blood picture, renal function tests, liver function tests, and coagulation profile were done.

All patients were informed about the study design and objectives. A written informed consent was signed by every patient prior to the study.

\section{Intraoperative preparations:}

Demographic data of all patients as sex, age and weight were recorded. The basal heart rate (HR); noninvasive systolic and diastolic blood pressure (SBP) (DBP); and peripheral oxygen saturation $(\mathrm{SpO} 2)$ were recorded. An 18 gauge IV cannula was inserted in non-operated arm and Ringer's solution was infused all through the surgery. Oxygen nasal cannula was used with an oxygen flow rate of 3LPM.

Sedation in the form of midazolam $0.02 \mathrm{mg} / \mathrm{kg}$ with or without fentanyl $0.5-1$ $\mathrm{mcg} / \mathrm{kg}$ was administered to any of the patients who felt discomfort or could not tolerate the procedure.

Interscalene nerve block was done ultrasound-guided using a linear array ultrasound transducer $\left(7.5-12.5 \mathrm{MHz}^{*}\right.$ broadband, multifrequency transducer; HONDA ELECTRONICS, Tokyo, Japan). While the patient was in the supine position, the head was rotated to the contralateral side of the block.

After the completion of local anesthetic administration, the time was recorded as a baseline for the time interval ( 0 point) and all vital data were monitored.

For block success, local anesthetic must be visualized within the correct tissue plane of the interscalene groove. The block was considered successful when sensory (pin prick test) and reached score $\geq 1$ and motor block (Bromage test) of the nerves supplying the shoulder reached score 2 .

Any patient who at any time of surgery experienced discomfort or mild pain would be managed by IV Fentanyl $0.5-1 \mathrm{mcg} / \mathrm{kg}$ with or without Midazolam $0.02 \mathrm{mg} / \mathrm{kg}$ that could be repeated as appropriate and these doses would be recorded. If there was still no improvement, the patient would rescue to general anesthesia and would be excluded from the study.

\section{The following parameters were assessed and recorded:}

1-Assesment of sensory block: Sensory block was assessed at the shoulder area by pin prick test using a 3-point scale ${ }^{(6)}$ as follows: 0: Normal sensation.1: Loss of sensation of pin prick (analgesia). 2: Loss of sensation of touch (anesthesia). Onset time and duration of sensory block were recorded.

Onset time for sensory block is defined as the time interval between the completion of local anesthetic administration and the loss of sensation of pin prick performed every minute (sensory score $=1)^{(7)}$.

Duration of sensory block is defined as the time interval between the complete sensory block and complete resolution of anesthesia (score 0 for all nerves) ${ }^{(7)}$.

2- Assesment of motor block: Motor block assessment was done by the modified Bromagescale $^{(8)}$ which is a 3-point scale: Grade 0: Normal motor function with full flexion and extension of shoulder and elbow. Grade 1: Decreased motor strength Grade 2: Complete motor block with inability to move the shoulder. Onset time and duration of motor block were recorded for each patient.

Onset time for motor block is defined as the time interval between total local anesthetic administration and complete motor block (grade 2) i.e. inability to move the shoulder.

Duration of motor block is defined as the time interval from complete motor block (grade 2) to complete recovery of motor function of hand and forearm (grade 0$)^{(8)}$. 
All these data were recorded. Sensory and motor blocks were assessed every 5 minutes immediately after injection of the local anesthetic mixture for the first 15 minutes then every 15 minutes to the end of operation, then every $1 \mathrm{~h}$ after the surgery until block resolution.

3-Hemodynamic monitoring: HR, $\mathrm{SBP}, \mathrm{DBP}$ and $\mathrm{SpO} 2$ were recorded at 0,5 , $10,15,30,60,90$, and 120 minutes.
4- Sedation score: Sedation was assessed at $0,5,10,15,30,60,90$, and 120 minutes. The Ramsay Sedation Scale ${ }^{(9)}$ (table 1) was used and a score from 1-6 was given. The highest score for each patient was recorded.

5- Duration of surgery: The time between the onset of skin incision and the time of skin closure was recorded for every patient.

Table (1): Ramsay sedation scale ${ }^{(9)}$

\begin{tabular}{|l|l|}
\hline $\mathbf{1}$ & Anxious, agitated, restless. \\
\hline $\mathbf{2}$ & Cooperative, oriented, tranquil. \\
\hline $\mathbf{3}$ & Responds to commands only. \\
\hline $\mathbf{4}$ & Brisk response to light glabellar tap or loud noise. \\
\hline $\mathbf{5}$ & Sluggish response to light glabellar tap or loud noise. \\
\hline $\mathbf{6}$ & No response. \\
\hline
\end{tabular}

6- Duration of analgesia (DOA) of the interscalene nerve block: The time of request of first analgesia by the patient was recorded. Duration of analgesia is defined as the time between the complete sensory block and the first postoperative analgesic request. It was recorded for every patient.

7- Assesment of postoperative pain: Postoperative pain will be recorded at $0.5,1$, $2,4,8,12,16,24 \mathrm{hrs}$ postoperative at rest and on movement by using visual analogue scale (VAS).Intravenous pethidine sulfate was used for postoperative analgesia (rescue analgesia). The analgesic dose of pethidine was $0.5 \mathrm{mg} / \mathrm{kg} /$ dose to be repeated on demand (VAS is $\geq 3$ ), provided that the total 24-hour dosage did not exceed $1 \mathrm{mg} / \mathrm{kg}$ every 8 hours. If the patient complained of pain in between scheduled doses of pethidine (1 $\mathrm{mg} / \mathrm{kg}$ every 8 hours), paracetamol $15 \mathrm{mg} / \mathrm{kg}$ was given intravenously with a maximum dose of $1000 \mathrm{mg}$ per time. The total 24hour analgesic requirements were calculated and recorded for each patient.
8- Recording adverse effects and/or complications: Any complication related to the block technique e.g. pneumothorax, hoarseness of voice, phrenic nerve affection or adverse effects of the drugs used [e.g. hypotension $(20 \%$ decrease below the baseline value), bradycardia (HR $<50$ beats/min), nausea, vomiting, and hypoxemia $\left.\left(\mathrm{SpO}_{2}<90 \%\right)\right]$ or any other complications were recorded.

\section{RESULTS}

75 patients of either sex, ASA I and II status were enrolled in this study. They were divided into 3 equal groups each containing 25 patients. All the patients completed the study.

\section{1) Demographic data and duration of surgery:}

There was no significant difference in all the parameters compared between the 3 groups as shown in (table 2). 
Table (2):Demographic data and duration of surgery.

\begin{tabular}{|l|c|c|c|c|c|}
\hline \multicolumn{1}{|c|}{ Variables } & Group C & Group D & Group F & \multicolumn{2}{c|}{ Tests } \\
\cline { 4 - 6 } & $(\mathbf{n = 2 5})$ & $(\mathbf{n = 2 5 )}$ & $\mathbf{f}=\mathbf{2 5})$ & $\mathbf{f}^{\mathbf{2}}$ & P-value \\
\hline Age (years) & $42.2 \pm 5.2$ & $42.2 \pm 2.9$ & $42.1 \pm 3.1$ & 0.006 & 0.994 \\
\hline Sex (M/F) & $14 / 11$ & $12 / 13$ & $10 / 15$ & 1.282 & 0.526 \\
\hline Weight (Kg) & $76.76 \pm 2.6$ & $75.14 \pm 4.3$ & $74.9 \pm 0.5$ & 3.011 & 0.056 \\
\hline Duration of surgery(min) & $104.6 \pm 5.1$ & $105.4 \pm 4.5$ & $102.3 \pm 5.7$ & 2.467 & 0.092 \\
\hline
\end{tabular}

Data are presented as Mean \pm SD or ratio.(n) $=$ the number patients.P $>0.05=$ non-significant.

2) Assessment of onset and duration of sensory and motor block:There was statistically significance difference with $P<$ 0.05 between study groups as regards total sensory and motor duration, with high mean among Group D sensory $920 \pm 68.79$ and motor $788 \pm 66.7$, low mean among Group C sensory $660 \pm 41.28$ and motor $580 \pm 54.5$, and Group $F$ between the two groups with sensory $799 \pm 51.05$ and motor $691 \pm 59.4$ as shown in (table 3).

Table (3): Onset and duration of sensory and motor block.

\begin{tabular}{|l|c|c|c|c|c|}
\hline & \multirow{2}{*}{ Group C } & \multirow{2}{*}{ Group D } & \multirow{2}{*}{ Group F } & \multicolumn{2}{|c|}{ Tests } \\
\cline { 5 - 6 } & & & $\mathrm{f}$ & P-value \\
\hline Onset of sensory block (min) & $28.00 \pm 4.10$ & $18.00 \pm 3.08$ & $22.00 \pm 4.12$ & 43.910 & $<0.001^{* *}$ \\
\hline Duration of sensory block (min) & $660 \pm 41.28$ & $920 \pm 68.79$ & $799 \pm 51.05$ & 140.400 & $<0.001^{* *}$ \\
\hline Onset of motor block (min) & $29.00 \pm 4.10$ & $22.00 \pm 5.03$ & $24.00 \pm 4.57$ & 11.112 & $<0.001^{* *}$ \\
\hline Duration of motor block (min) & $580 \pm 54.5$ & $788 \pm 66.7$ & $691 \pm 59.4$ & 74.211 & $<0.001^{* *}$ \\
\hline
\end{tabular}

Data were presented as mean and SD ** Highly significant $\mathrm{SD}=$ Standard deviation

Moreover, there is statistically significance difference with $\mathrm{P}<0.05$ between study groups as regards onset of sensory and motor duration, with low mean among Group D sensory $18.00 \pm 3.08$ and motor $22.00 \pm 5.03$, high mean among Group C sensory $28.00 \pm 4.10$ and motor $29.00 \pm$ 4.10 , and Group $\mathrm{F}$ between the two groups with sensory $22.00 \pm 4.12$ and motor 24.00 \pm 4.57 .

Table (4):Highest sedation score

\begin{tabular}{|c|c|c|c|c|c|c|}
\hline \multirow{2}{*}{ Sedation score } & \multicolumn{6}{|c|}{ Groups } \\
\cline { 3 - 8 } & \multicolumn{2}{|c|}{ Group C } & \multicolumn{2}{c|}{ Group D } & \multicolumn{2}{c|}{ Group F } \\
\cline { 3 - 8 } & $\mathrm{N}$ & $\%$ & $\mathrm{~N}$ & $\%$ & $\mathrm{~N}$ & $\%$ \\
\hline 2 & 25 & 100.0 & 15 & 60.0 & 25 & 100.0 \\
\hline 3 & 0 & 0.0 & 10 & 40.0 & 0 & 0.0 \\
\hline Total & 25 & 100.0 & 25 & 100.0 & 25 & 100.0 \\
\hline $\begin{array}{c}\text { Chi-square } \\
\text { test }\end{array}$ & $\mathrm{X}^{2}$ & \multicolumn{7}{|c|}{30.000} \\
\cline { 2 - 7 }
\end{tabular}

$\mathrm{N}=$ the number patients. $\%=$ percentage of patients. $\mathrm{P}<0.001=$ highly significant.

\section{3) Assessment of sedation:}

Each patient was assessed using Ramsay scale of sedation at $0,5,10,15,30$, 60,90 , and 120 minutes. The highest score for each patient was recorded and all highest scores were statistically compared (Table 4). Patients of group $\mathrm{C}$ and $\mathrm{F}$ have got scores of 2. In group D (Dexmedetomidine group), 15 patients have got a score of 2 and 10 patients have got a score of 3 which is statistically highly significant difference from the other 2 groups $(\mathrm{P}<0.001)$. 
4) Assessment of the duration of analgesia (DOA):

Group D had the longest duration of analgesia and group $\mathrm{C}$ had the shortest. There was a highly significant difference between group $\mathrm{D}$ and group $\mathrm{C}(\mathrm{P}<0.001)$.
A highly significant difference existed also between group $\mathrm{C}$ and $\mathrm{F}(\mathrm{P}<0.001)$. Additionally, there was a significant difference between group $\mathrm{D}$ and group $\mathrm{F}(\mathrm{P}$ $=0.025)$ as shown in (Table 5).

Table (5): Duration of analgesia of the block.

\begin{tabular}{|c|c|c|c|}
\hline \multirow[t]{2}{*}{ Duration of analgesia (hours) } & \multirow{2}{*}{ Mean \pm SD } & \multicolumn{2}{|c|}{ ANOVA } \\
\hline & & $\mathrm{F}$ & P-value \\
\hline Group C & $13.5 \pm 1.39$ & \multirow{3}{*}{23.423} & \multirow{3}{*}{$<0.001^{* *}$} \\
\hline Group D & $16.0 \pm 1.17$ & & \\
\hline Group F & $14.5 \pm 1.33$ & & \\
\hline \multicolumn{4}{|c|}{ Tukey's test } \\
\hline C \& D & $\mathbf{C} \& \mathbf{F}$ & \multicolumn{2}{|c|}{$\mathbf{D} \& \mathbf{F}$} \\
\hline$<0.001 * *$ & $<0.001 * *$ & \multicolumn{2}{|c|}{$0.025^{*}$} \\
\hline
\end{tabular}

Data are presented as mean \pm SD.P $<0.05=$ significant.P $<0.001=$ highly significant.

5) Assessment of postoperative pain:

Recording of VAS of each patient at $0.5,1,2,4,6,12$ and 24 hrs. postoperatively and statistical analysis for all patientsshowed that patients of group $\mathrm{C}$ had a score of more than 3 more rapidly than groups $\mathrm{D}$ and $\mathrm{F}$. Similarly, patients of group F had VAS of more than 3 earlier than group D.

Postoperative analgesic requirement was recorded for each patient as the number of doses of pethidine needed. Patients were divided into those who needed a single dose and those who needed more as shown in (Table 6), In group D, 24 patients needed a single dose of pethidine $(0.5 \mathrm{mg} / \mathrm{Kg})$ and only one patient needed a second dose. There was highly significant difference between group $\mathrm{D}$ and both groups $\mathrm{C}$ and $\mathrm{F}$ as regards the number of patients who needed a second dose of pethidine (16 and 15 respectively) $(\mathrm{P}<0.001)$.

Table (6): Comparison of the numbers of postoperative doses of pethidine in the study groups

\begin{tabular}{|c|c|c|c|c|c|c|c|}
\hline \multirow{3}{*}{\multicolumn{2}{|c|}{ Pethidine (mg/kg) }} & \multicolumn{6}{|c|}{ Groups } \\
\hline & & \multicolumn{2}{|c|}{ Group C } & \multicolumn{2}{|c|}{ Group D } & \multicolumn{2}{|c|}{ Group F } \\
\hline & & $\mathbf{N}$ & $\%$ & $\mathbf{N}$ & $\%$ & $\mathbf{N}$ & $\%$ \\
\hline \multicolumn{2}{|c|}{$0.5 \mathrm{mg} / \mathrm{kg}$ (single dose) } & 9 & 36 & 24 & 96.0 & 10 & 40.0 \\
\hline \multicolumn{2}{|c|}{$1 \mathrm{mg} / \mathrm{kg}$ (two doses) } & 16 & 64 & 1 & 4.0 & 15 & 60.0 \\
\hline \multicolumn{2}{|c|}{ Total } & 25 & 100.0 & 25 & 100.0 & 25 & 100.0 \\
\hline \multirow[t]{2}{*}{ Chi-square } & $\mathrm{X}^{2}$ & \multicolumn{6}{|c|}{18.054} \\
\hline & P-value & \multicolumn{6}{|c|}{$<0.001$} \\
\hline
\end{tabular}

$\mathrm{N}=$ the number patients.

$\%=$ percentage of patients.

$\mathrm{P}<0.001=$ highly significant. 


\section{6) Assessment of Hemodynamic changes:}

Systolic blood pressure (SBP), diastolic blood pressure (DBP), and heart rate (HR) were recorded intraoperatively and were statistically compared respectively. Patients in group D showed a statistical significant decrease of SBP, DBP as well as HR compared to group $\mathrm{C}$ and $\mathrm{F}$.

7) Adverse effects and complications: No adverse effects or complications related to the procedure, or to the study drugs were recorded in any patient in the three study groups.

\section{DISCUSSION:}

In the current study, 75 patients were randomly divided into 3 equal groups. Patients of group $\mathrm{C}$ received bupivacaine $(0.5 \%)$ only. In group D 100 micrograms of dexmedetomidine were added to bupivacaine. Patients of group F received 50 micrograms of fentanyl in addition to bupivacaine. All patients received equal volumes of 30 milliliters.

Regarding the assessment of sensory block in the current study, adding dexmedetomidine in group $\mathrm{D}$ significantly fastened the onset of sensory block with a highly significant difference $(\mathrm{P}<0.001)$ in comparison to group $\mathrm{C}$, and a significant difference in comparison to group $\mathrm{F}(\mathrm{P}=$ 0.022). Not only dexmedetomidine fastened the onset of the sensory block, but also it prolonged the duration of the block.

In the current study, when group $\mathrm{F}$ was compared to group $\mathrm{C}$, it was found that addition of fentanyl to bupivacaine also significantly prolonged the duration of sensory block. However, the duration of sensory block in group $\mathrm{F}$ was less than that in group $\mathrm{D}$.

The same result was also obtained by Karakaya and his colleagues ${ }^{(10)}$, using 2.5 micro-gram of fentanyl / $\mathrm{ml}$ of bupivacaine. they got out the same effect in comparison with the control group (earlier onset and prolonged duration of the sensory block).

Also, in the current study, it was noticeable that dexmedetomidine group showed a greatly faster onset of motor block when compared to the other two groups.

Similar result was also found by Aggarwal and his colleagues (7) when they added 100 micrograms of dexmedetomidine to $30 \mathrm{ml}$ of bupivacaine $0.325 \%$ in 50 patients scheduled for hand and forearm surgery under supraclavicular brachial plexus nerve block. The dexmedetomidine group showed a faster onset and a prolonged duration of motor block compared to the bupivacaine group with a high statistical significant difference $(\mathrm{P}<$ $0.001)$.

Regarding sedation of the patients during surgery measured according to Ramsay sedation score, the collected data showed that dexmedetomidine has got a superadded advantage of sedation. Ten out of twenty-five patients in the dexmedetomidine group (group D) have got a sedation score of 3 , while none of the patients in the other two groups (group $\mathrm{C}$ and $\mathrm{F}$ ) has got a score more than 2 . This was a highly statistically significant difference and a clinically favorable effect.

The same result was also reported by Kaygusuz and his colleagues ${ }^{(11)}$ where they added the same dose (100 micro-grams) of dexmedetomidine to bupivacaine used in axillary nerve block. This was done in 60 patients undergoing hand and forearm surgery who were divided into two groups. Dexmedetomidine group got a noticeable sedation effect compared to the other group.

As regards postoperative analgesia and the total postoperative analgesic consumption, the current study showed that in group D (dexmedetomidine group) compared to group $\mathrm{C}$ (control group) and group F (fentanyl group), there was a significant prolongation of the duration of postoperative analgesia. Patients of group D needed less doses of 
postoperative pethidine as compared to groups $\mathrm{C}$ and $\mathrm{F}$.

A similar result was also obtained by Das and his colleagues ${ }^{(12)}$ who used the same dose (100 micro-grams) of dexmedetomidine added to $30 \mathrm{ml}$ of ropivacaine $(0.5 \%)$ in supraclavicular nerve block in upper limb surgery. The study included 84 patients divided into two groups and they used an intramuscular injections of diclofenac sodium for postoperative analgesia. They noticed that dexmedetomidine group received much less dosage of rescue analgesia than the other group (ropivacaine group) with a statistical high significance.

As regards hemodynamic data in the current study, systolic blood pressure (SBP), diastolic blood pressure (DBP) and heart rate (HR) were recorded althrough the operation. Patients in group D showed a statistical significant decrease of SBP, DBP as well as HR compared to group C and F. However, these changes in hemodynamics did not progress to a critical level (bradycardia $<50$ bpm) or sever hypotension (defined by decrease in mean arterial pressure below $20 \%$ of the baseline or systolic BP $[\mathrm{SBP}]<90$ $\mathrm{mmHg}$ ) that needed any intervention.

In contrast to the current study Aliye and his colleagues ${ }^{(13)}$ recorded severe bradycardia in 7 patients out of 30 when they added 100 micrograms of dexmedetomidine to levobupivacaine $0.5 \%$ compared to a control group in which $30 \mathrm{ml}$ of levobupivacaine $0.5 \%$ was used alone. There was a statistically significant difference $(\mathrm{P}<0.005)$ between their two groups.

Concerning the side effects in the current study, none of the patients in the three groups had experienced any side effect or complication either of the anesthetic technique (e.g. pneumothorax, hematoma) or of the used drugs (eg. sever hypotension, bradycardia, nausea, vomiting or hypoxia).

In contrast to the current study, Karakaya and his colleagues ${ }^{(10)}$ reported a single case of nausea and a single case of dizziness in their study in the group where they used fentanyl (100 micrograms) added to $40 \mathrm{ml}$ bupivacaine $(0.125 \%)$ compared to their control group where they used bupivacaine alone in axillary brachial plexus block. The higher dose of fentanyl used may explain the occurrence of such side effects.

\section{Conclusions:}

In the current study, it was obvious that:Addition of dexmedetomidine was better in prolongation of the duration of interscalene brachial plexus block and improvement of postoperative analgesia than fentanyl and bupivacaine alone without significant adverse effects in patients undergoing upper limb surgeries.

\section{REFERENCES:}

1. Van Geffen GJ, Moayeri N, Bruhn Jr, et al.; Correlation between Ultrasound Imaging, Cross-Sectional Anatomy, and Histology of the Brachial Plexus: A Review. Regional Anesthesia and Pain Medicine 2009; 34: 4907.

2. Esmaoglu A, Yegenoglu F, Akin Aand Turk CY: Dexmedetomidine added to levobupivacaine prolongs axillary brachial plexus block. Anesth Analg 2010; 111:1548-1551.

3. Carollo DS, Nossaman BD, Ramadhyani U: Dexmedetomidine: A review of clinical applications. Curr Opin Anaesthesiol 2008; 21:457-61.

4. Yoshitomi T, Kohjitani A, Maeda S, et al: Dexmedetomidine enhances the local anesthetic action of lidocaine via an alpha-2A adrenoceptor. Anesth Analg 2008; 107: 96101.

5. Gormley WP, Murray JM, Fee JP, et al.: Effect of the addition of alfentanil to lignocaine during axillary brachial plexus anaesthesia. Br J Anesth1996; 76: 802-5.

6. Macleod J, Munro JF and Campbell IW: Neurological examination. In: Macleod's Clinical Examination, Haris P Y (eds.), Churchill Livingstone. $5^{\text {th }}$ edition 2000 ; 764 770 .

7. Agarwal S, Aggarwal $\mathrm{R}$ and Gupta P:Dexmedetomidine prolongs the effect of 
bupivacaine in supraclavicular nerve block; Journal of anesthesiology clinical pharmacology 2014; (30):36-40.

8. Sarkar DJ, Khurana G, Chaudhary AandWallyna A: A comparative study on the effects of adding fentanyl and buprenorphine to local anaesthetics in brachial plexus block. J Clin Diagn Res 2010; 4:3337-43.

9. Ramsay MA, Savage TM, Simpson B Rand Kantouga G: Controlled sedation with alphaxolone-alphadolone. Br Med J 1976; 2:656-9.

10. Karakaya D, Buyukgoz F, Baris S, GuldogusFand Tur A: Addition of fentanyl to bupivacaine prolongs anesthesia and analgesia in axillary brachial plexus block. Reg Anesth Pain Med. 2001; 26(5):434-8.
11. Kaygusuz K, Kol IO, Duger C, Gursoy S, Ozturk H, Kayacan U, Aydin R, Mimaroglu C: Effect of adding Dexmedetomidine to levobupivacaine in axillary brachial plexus block, Current therapeutic research 2012; (73):103-111.

12. Das A, Majumdar S, Kundu Rand Mandal SK: Effect of dexmedetomidine as adjuvant in ropivacaine-induced supraclavicular brachial plexus block: Saudi J. Anesthesia 2014; (8):72-77.

13. Aliye E, Fusun $Y$, AynurAandCemilYidririm Turk: Dexmedetomidine added to levobupivacaine prolongs axillary brachial plexus block, anesthesia analgesia2010; (111):15481552

دراسة مقارنة بين عقار الديكسميديتوميدين والفينتانيل كمكل علاجي للبوبيفاكايين في إحصار الضفيرة

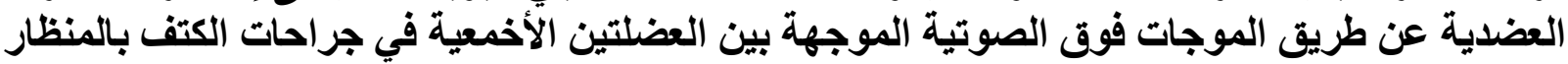

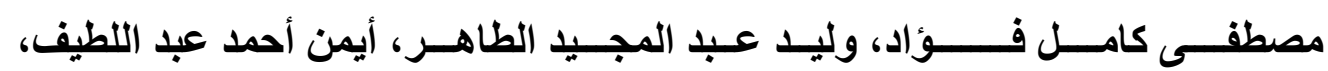
سارة حسام الاين طه محمد

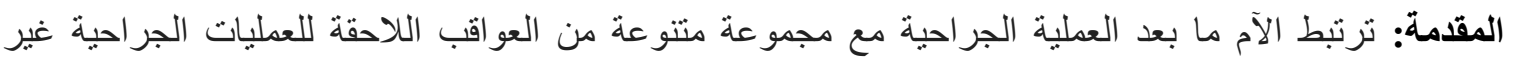

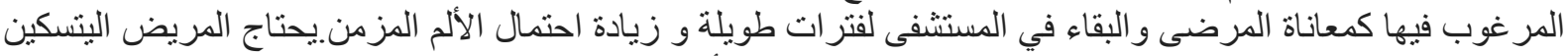

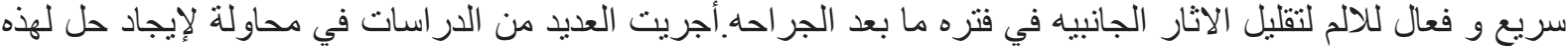

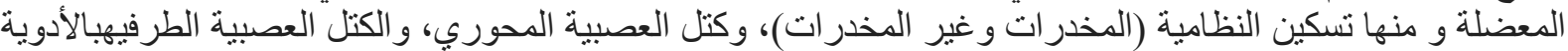
التقليدية أو مع إضافه عقاقير اخري بجرعات مختلفة، مع ذلك أظهر كل أثر جانبها الأمر الذي يحد من استخدامها لحالات الكية الكرات

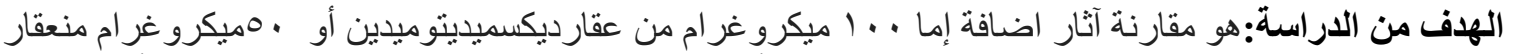

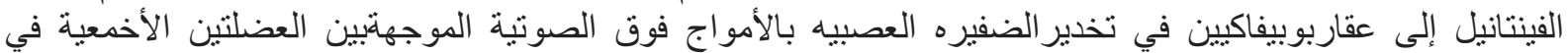

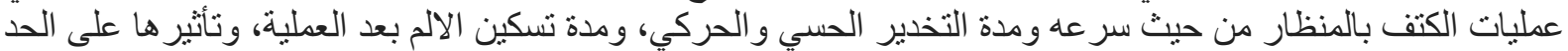

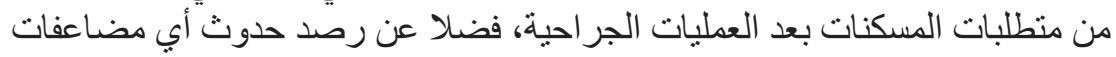

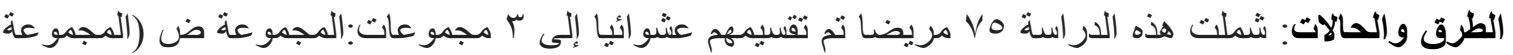

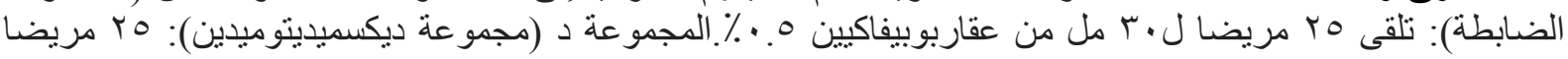

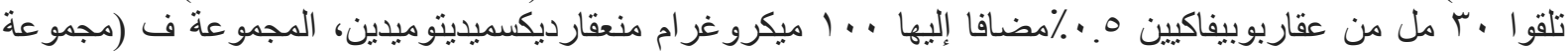

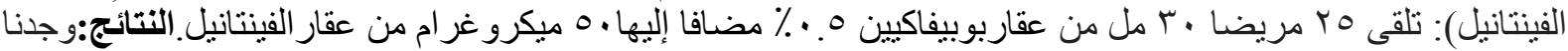

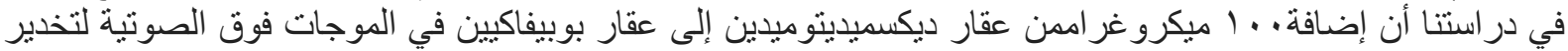

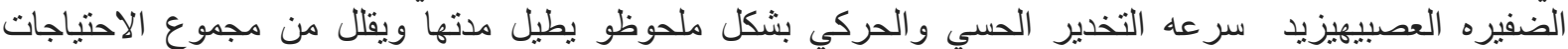

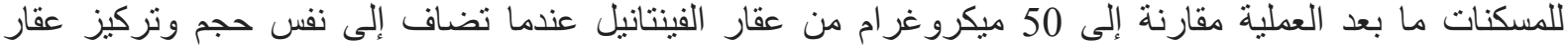

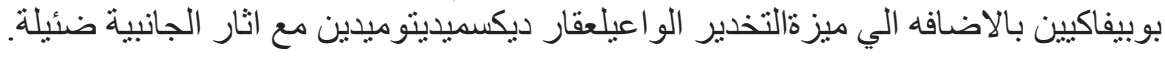

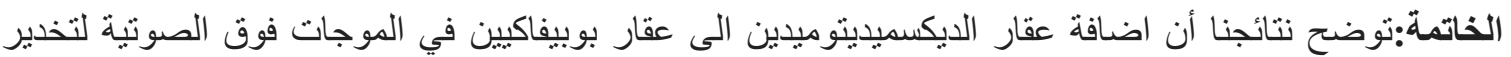

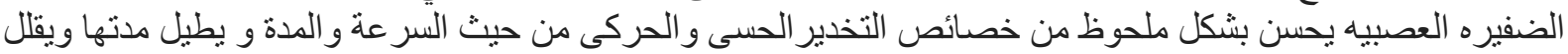
من مجموع الاحتياجات للمسكنات ما بعد العملية مقارنة إلى اضافة عقار الفينتانيل إلى نفس حجم وتركيز عقار بو بيفاكيين، و عند استخدام البوبيفاكين دون أي اضافات. 